\title{
Future Challenges for Academic-Industry Value Co-Creation Through Lifelong Learning
}

\author{
Carina Sjödin, Leo Hatvani, Anders Olsson \\ Mälardalen University, Sweden \\ carina.sjodin@mdh.se \\ leo.hatvani@mdh.se \\ anders.olsson@mdh.se
}

\begin{abstract}
The presented research aims to explore future context of e-learning, needs of professionals, and how higher education can respond to those needs. This is an empirical study with a qualitative approach. We interviewed teachers and students about their perceptions of e-learning. The interviews were semi-structured and allowed for reflections. All students interviewed were currently employed in industry and active e-learners. A web-based horizon scanning was made to identify trends in order to understand future context. The study is part of an academic development project with the intention of strengthening academic capacity and company knowledge to stay competitive in an international setting. In this paper, we present several cornerstones for creating courses that are suitable for professionals. Administrative routines and procedures need to be adjusted in order to meet challenges from other actors and the needs of stakeholders. A seamless experience would be preferred from a consumer-oriented perspective, where flexibility is a key factor. This flexibility is manifested by the need to control their own workload to adjust the work-education balance. Locus of learning needs to be problematized. Students do not identify themselves as co-creators. This is a challenge to overcome in order to design for the work-study situation. Previous studies on distance learning have mostly focused on full time students in today's context. This study involves foresight and the situation for students in employment. The findings will be relevant for teachers in the design phase of a course intended for any type of student who is not a traditional full-time student, and for university management building a strategy for the future of e-learning.
\end{abstract}

\section{Introduction}

Demographic development and the need for industry to transform and be responsive to trends and tendencies that comes with globalization, digitalization, lifelong learning, sharing economy and a growing market for a new generation of educational institutions. Pucciarelli and Kaplan (2016) present three core challenges for institutions in higher education to address in the near future. They involve competition and market share, a mindset change towards entrepreneurship and involvement of stakeholders in co-creation. Web-based education gives universities an opportunity to offer its courses to new target groups, both nationally and internationally. It allows for widening recruitment and increased inclusion. In addition to course development, universities also need to work on developing support functions that are particularly relevant for web-based courses, for example in building up competence and administrative support around admission, validation, ICT support, internationalization and marketing.

Universities have extensive cooperation with business in the form of a large number of research projects. Recently the demands that the universities need to contribute to the professional's skill development have increased. The strategy meets two sides of the business sector's competence needs; partly increased businessrelevant knowledge among young students and partly corporate need for skills development for employees. This new landscape involves challenges for universities and a need to learn more about different stakeholders' perspectives.

\section{Theoretical background}

A number of trends affect the future of higher education and this means that universities need to handle change, complexity, challenges and uncertainties (Pucciarelli and Kaplan, 2016). Among the opportunities are millennials seeking augmented educational experience, and also a growing and changing student population. Globalization involves a broadening competitive challenge (Pucciarelli and Kaplan, 2016). For Pucciarelli and Kaplan (2016) one strategic recommendation is to increase connections, interactions and co-creation of value with an increased number of stakeholders. This may involve a more dialogue-based communication and a new design of learning processes and structures. Scholars (Pucciarelli and Kaplan, 2016) also suggest another strategic focus: evolving requirements of the job market and employability. 
The discussion about students being viewed as customers in higher education or not needs to end (Guilbault, 2018). The important issue is whether universities are market oriented and able to understand user needs. Guilbault (2018) suggests that it would be beneficial to talk about students as co-creators instead, according to a service dominant logic. Vargo and Lusch (2004) claimed that customers or users are always co-creators of value. Value-in-use is a central theme for the service-dominant logic, which makes user context important to understand. Higher education requires engagement from stakeholders and needs to be recognized as a service (Guilbault, 2018).

There are people-related barriers in higher educational institutions, and they involve resistance to change, teachers' disengagement, and student's attitudes (Lašáková, Bajzíková and Dedze, 2017). Among their suggestions to deal with innovation in higher educational institutions are efforts to strengthen collaboration with external stakeholders.

\section{Method}

This study was made with a qualitative approach based on empirical data. Two different methods have been used to generate data. By using web-based horizon scanning, we looked for emergent trends and tendencies. Both established trends and weak signals were identified.

As our second method, we performed a series of semi-structured interviews aiming to better understand the context and needs among students in existing distance courses who also work full time, and teachers ${ }^{1}$ teaching those courses. For student interviews, an open invitation was presented in a course setting. Semi structured deep interviews with teachers involved in designing and executing eight distance courses on an advanced level specially focusing on students in company settings with at least one year of work experience. Analysis was made through thematic coding.

\section{Preliminary results}

The findings are still tentative as the research project is in the final stage regarding the analysis of empirical data. Political trends include a focus on lifelong and adult learning and the need for industry to transform in order to stay competitive. European Commission outlined these challenges as a significant part of the 2030 Agenda for Sustainable Development (Goals 4 and 9) (UN General Assembly, 2015). Other challenges include cooperation between universities and business and also development of skills and learning mobility (European Commission, 2018). Open access is only one example of how the sharing economy will affect higher education. Students express a need to share both course material and assignments with co-workers. Today this is a grey zone for students since access is limited.

Group assignments can cause difficulties and students often describe them as a source for frustration and conflicts. Student-student interactions are not described as important as student-teacher interactions. Students are interested in a community within the subject studied, but it needs to be uncoupled from the course.

A seamless experience would be preferred from a student as a consumer-oriented perspective, where flexibility is a key factor. This flexibility is manifested by the need to control their own workload to adjust the workeducation balance

We have identified a number of challenges specific to lifelong learning and distance courses compared to the traditional educational setting. The first barrier towards successful lifelong education for the students is that often their place of work is not in agreement regarding their need for further education. This can effectively remove the students' ability to partake in education during their work-hours. When there is such an agreement and an identified need; companies tend to push students towards corporate education or commercial educational providers rather than public universities. Reasons for this vary, but timing and planning matter.

\footnotetext{
${ }^{1}$ We would like to thank the teachers from Mälardalen University's lifelong learning programs (https://www.mdh.se/utbildning/livslangtlarande?l=en UK) for the time invested in the interviews.
} 
Second barrier is that even with strong intrinsic (and/or extrinsic) learning motivations, a group of students, fully employed in traditional work environments, cannot allocate the same hours to collaborate on the projects required to complete many traditional courses. This leads to low student engagement, difficulty in meeting deadlines, and low course completion rate.

Third barrier resulting from fulltime employment is that student's access to the digital educational systems is often limited in their workplace. This is especially visible with distance courses that provide lecture recordings or supplementary materials using popular digital entertainment platforms.

Fourth, by losing the structure of the course, the students lose one incentive guiding them towards course completion.

\section{Discussion}

For students, successful participation in a lifelong learning course can increase their future employability and thus reduce the total spending of the social support system. In our findings, the main facilitator of the increased participation in lifelong learning on advanced level would be if their employers make it a welcome activity for employees. However, the employers often lack the incentive to make their employees qualified for jobs that they are currently not assigned.

In this context, it is necessary to look for solutions where the courses can be adapted for students with sporadic participation. To achieve this, the courses should not rely on rigid schedules. Deadlines can be either removed, made optional, or made relative to the start of work on the assignment. Teachers should also be aware of the restrictions when creating collaborative moments in the course. A structure for asynchronous work on assignment is almost always well utilized by students when it is present and collaborative work is required. Additional incentive towards finishing of the course should be built into the courses to increase completion rates closer to those of otherwise unemployed students.

Co-creation in higher education according to a service logic can be a useful strategy as well as method in order to respond to these challenges. This is not a new idea. Eraut (1985) recognized the need for universities to reconsider their role and to move from being a creator and provider of generalizable knowledge to institutions with the role of enhancing the knowledge creation capacities of others, both individuals and professional communities. Students do not yet identify themselves as co-creators. This is a challenge to overcome in order to design for the work-study situation. Locus of learning is partly shifting and takes place in contexts outside of universities. This need for flexibility in time is a challenge for universities. It challenges the way teachers are organized and scheduled. This is a consequence of a user-centric perspective.

\section{Conclusions}

From a university perspective there is a need to reconsider the identity as an educator for youth. With the advancement of technologies many jobs are automated and higher skilled workers are required to monitor, control, and maintain the automation. This presents us with a future where lifelong learning is necessary to preserve industrialized society. However, at the moment, there are almost no incentives for employers to enable this type of learning, thus courses have to be adapted to students who are learning outside of the standard working hours and traditional structures. This can be achieved by introducing more flexibility into the courses as well as augmenting courses with systems that would incentivize completion outside of the traditional certificates and grades. These kinds of courses need to be designed for increased openness and to communicate through platforms enabling a relational approach for all stakeholders to enable co-creation of value in higher education.

\section{References}

Eraut, M. (1985) "Knowledge creation and knowledge use in professional contexts", Studies in Higher Education, 10 (2), pp 117-133.

European Commission, Directorate-General for Education, Youth, Sport and Culture (2018) Education and training monitor 2018, Publications Office of the European Union, Luxembourg. 
Guilbault, M. (2018) "Students as customers in higher education: The (controversial) debate needs to end", Journal of Retailing and Consumer Services, No. 40, pp 295-298.

Lašáková. A., Bajzíková, L. and Dedze, I. (2017) "Barriers and drivers of innovation in higher education: Case study-based evidence across ten European universities". International Journal of Educational Development, No. 55, pp 69-79.

Pucciarelli, F. and Kaplan, A. (2016) "Competition and strategy in higher education: Managing complexity and uncertainty", Business Horizons, No. 59, pp 311-320.

UN General Assembly (2015) Transforming our world: the 2030 Agenda for Sustainable Development, Resolution adopted by the General Assembly.

Vargo, S.L., and Lusch, R.F. (2004) "Evolving to a new dominant logic for marketing", Journal of Marketing, Vol. 68, No. 1, pp. 1-17. 